Article

\title{
Trend Analysis on Adoption of Virtual and Augmented Reality in the Architecture, Engineering, and Construction Industry
}

\author{
Mojtaba Noghabaei ${ }^{1, *(\mathbb{D})}$, Arsalan Heydarian ${ }^{2}$, Vahid Balali ${ }^{3}{ }^{[}$and Kevin Han ${ }^{1}$ (D) \\ 1 Department of Civil, Construction, and Environmental Engineering, North Carolina State University, \\ Raleigh, NC 27695, USA; kevin_han@ncsu.edu \\ 2 Department of Engineering Systems and Environment, Link Lab, University of Virginia, \\ Charlottesville, VA 22903, USA; heydarian@virginia.edu \\ 3 Department of Civil Engineering and Construction Management, California State University, Long Beach, \\ CA 90840, USA; Vahid.Balali@csulb.edu \\ * Correspondence: snoghab@ncsu.edu
}

Received: 25 December 2019; Accepted: 4 March 2020; Published: 13 March 2020

check for updates

\begin{abstract}
With advances in Building Information Modeling (BIM), Virtual Reality (VR) and Augmented Reality (AR) technologies have many potential applications in the Architecture, Engineering, and Construction (AEC) industry. However, the AEC industry, relative to other industries, has been slow in adopting AR/VR technologies, partly due to lack of feasibility studies examining the actual cost of implementation versus an increase in profit. The main objectives of this paper are to understand the industry trends in adopting AR/VR technologies and identifying gaps within the industry. The identified gaps can lead to opportunities for developing new tools and finding new use cases. To achieve these goals, two rounds of a survey at two different time periods (a year apart) were conducted. Responses from 158 industry experts and researchers were analyzed to assess the current state, growth, and saving opportunities for AR/VR technologies for the AEC industry. The findings demonstrate that older generations are significantly more confident about the future of AR/VR technologies and they see more benefits in AR/VR utilization. Furthermore, the research results indicate that Residential and commercial sectors have adopted these tools the most, compared to other sectors and institutional and transportation sectors had the highest growth from 2017 to 2018. Industry experts anticipated a solid growth in the use of AR/VR technologies in 5 to 10 years, with the highest expectations towards healthcare. Ultimately, the findings show a significant increase in AR/VR utilization in the AEC industry from 2017 to 2018.
\end{abstract}

Keywords: virtual reality; augmented reality; building information modeling; industry trend; virtual environment

\section{Introduction}

One of the largest industries in the United States is the Architecture, Engineering, and Construction (AEC) industry with expenditure reaching over $\$ 1.162$ trillion in 2017 [1]. However, over $98 \%$ of construction projects incur cost overruns and delays [2]. Many projects experience rework, costing $5 \%$ to $20 \%$ of the total contract value [3]. The main causes of rework include lack of communication among different construction parties, lack of adequate visualization capability to recognize design conflicts, and lack of support for advanced communication technologies [4,5]. Addressing these deficiencies can decrease the number of unforeseen issues and, therefore, rework in construction projects [5].

Over the past decade, Building Information Modeling (BIM) has found a wide range of applications in the AEC industry [6-10]. Global reports indicate that currently BIM is utilized heavily by AEC 
companies and within one year more than $90 \%$ of the entire industry will completely utilize BIM in their projects [11]. In this paper, BIM is defined as the process of generating and involving a digital representation of a building or construction and their characteristics. BIM is not just the production of 3D models [12], therefore, it can be used for different functions such as improving communication, decision making enhancement, and visualization. Furthermore, BIM can accelerate information integration from design to construction [13]. BIM technology has improved and revolutionized the way designers, engineers, and managers think about the buildings and enables them to predict and solve problems that might occur during the life-cycle of a building. BIM technology has enabled designers and engineers to detect clashes and simulate different construction scenarios for more efficient decision making. It revolutionized the AEC industry in many different aspects, such as technical aspects, knowledge management, standardization, and diversity management [14]. However, BIM still has some inherent shortcomings. For instance, BIM does not provide robust visualization for cluttered construction sites and the existing software packages provide limited user experience (i.e., lack of interactive visualization using a keyboard and mouse) [15]. Moreover, investigations have shown that BIM has some limitations in real-time on-site communication [16,17]. Additionally, the stakeholders who are not familiar with BIM solutions are not able to utilize its capabilities, such as improved communication through visualization and immersion.

To address some of the inherent deficiencies of BIM and open a new area for enhancement in AEC, researchers proposed the use of new technologies such as Augmented Reality (AR) and Virtual Reality (VR). In this paper, AR is referred to as a physical environment, whose elements are augmented with and supported by virtual input and VR is referred to as a simulated virtual environment, representing a physical environment. Accordingly, Immersive Virtual Environments (IVEs) are environments where user interaction is supported within a virtual environment. AR/VR technologies can potentially address these deficiencies and enhance BIM in several aspects, such as real-time on-site communication [16]. AR/VR can also improve communication among stakeholders and provide better visualization for engineers, designers, and other stakeholders, enabling one-to-one fully immersive experience [18]. Furthermore, IVEs have the necessary potentials to achieve knowledge synthesis to improve the design process [19].

Many industries implemented AR/VR in a successful way. For example, AR/VR has applications in manufacturing [20,21], retail [22,23], mining [24,25], education [26-28], and healthcare, especially for simulating surgeries [29-31]. Recent studies indicate the benefits of AR/VR in the AEC industry by demonstrating potential applications, such as safety training [32], visualization [33,34], communication [15], and energy management [35]. Although research suggests AR/VR technologies can be very effective, the AEC industry has been very slow in adopting these technologies, which could be partly due to lack of feasibility, examining the actual cost of implementation versus an increase in profit.

The main objectives of this study are to (1) determine the trends in adoption of AR/VR technologies in the AEC industry, (2) predict the future and vision of the industry experts on the adoption of these technologies, and (3) detect the limitations of the utilization of these technologies. The following section summarizes AR/VR studies in other domains and then in the AEC domain. The Method section lays out the main hypothesis and presents how the questionnaire was formulated and distributed to industry experts in order to achieve the three objectives above. Over 150 AEC industry experts have provided their feedbacks and visions on the growth and utilization of AR/VR technologies within the AEC industry. The questionnaire was designed to analyze the growth of these technologies by collecting responses at two different time intervals (2017 and 2018). With the analyzed survey results, the Survey Findings and Results section presents the industry trends from 2017 to 2018 and provides insights on the industry's visions on the future of AR/VR technologies and the main opportunities for the AEC industry. Finally, the Conclusion section summarizes the paper and discuss limitation and new potential applications for the AEC industry. 


\section{Literature Review}

In this section, the authors investigated applications of AR/VR technologies in AEC and other domains such as education, healthcare, mining industry, and retail industry. This comparison between AEC and other domains shows some of the potential use cases of AR/VR in the AEC industry.

\subsection{AR/VR in Other Domains}

Over the past decade, many researchers in different fields have investigated how AR/VR tools (In this paper, AR is referred to as a physical environment, whose elements are augmented with and supported by virtual input and VR is referred to as a simulated virtual environment, representing a physical environment. Accordingly, Immersive Virtual Environments (IVEs) are environments where user interaction is supported within a virtual environment) can enhance the communication of information among users. For instance, in the retail industry, [36,37] demonstrated that AR/VR applications are rapidly evolving and increasingly used over the past years. Researchers quantitatively analyzed more than 250 Mobile Augmented Reality (MAR) applications for shopping [22]. The results demonstrated that MAR is beneficial (i.e., efficiency or better shopping value) to the retail industry and presented actions to leverage MAR for smart retail.

In addition to the aforementioned industries, the mining industry is one of the pioneer industries in adopting AR/VR technologies. Researchers demonstrate that a VR solution can enhance occupational health and safety of coal mining workers by presenting a pilot study [38]. In this study, the workers were trained by professionals who had adequate experience with safety training. They tested different motion capture systems, Head-Mounted Displays (HMD), joysticks as input methods, and training scenarios and compared the results. The results showed that VR technology can be a very effective platform, substitute on-site training, and prevent trainees from exposure to dangers and risks that are common in a mining environment. The authors of [24] developed a VR-based training system for the mining industry and demonstrated that having more immersion using devices like magic leap can improve the training systems. The authors of [25] evaluated the VR-based safety training systems and concluded these systems have a positive learning experience.

AR/VR technologies have been receiving much attention in the healthcare industry due to their immersion capabilities. Researchers conducted a case study with over 500 hospital patients [39]. The patients viewed VR simulations such as ocean exploration and a tour of Iceland to reduce the stress level. Then, they conducted a survey on anxiety and pain level. The results demonstrated that most of the inpatient users expressed that the VR experience was pleasant and it was capable of reducing pain and anxiety. The authors of [40] designed a similar experiment with 50 patients. Patients viewed a 15-minute VR simulation called Pain RelieVR. This simulation is designed in a way that can reduce stress through a game-like experience. They monitored the heart rate and blood pressure of the patients during the experiment. The results of this experiment indicate that VR can significantly reduce pain versus traditional control distraction conditions. Researchers reviewed the applications of VR in the healthcare industry between 2005 and 2015 and concluded that VR had shown more success in three areas: eating disorders, pain management, and cognitive and motor rehabilitation [41]. Studies investigated the potentials of using AR/VR in neurosurgery [42]. They concluded that the healthcare industry needs more AR/VR tools for educational purposes.

There are also many researchers in education who have investigated AR/VR technology. Researchers presented a comprehensive review of usage, challenges, and advantages of AR technology in the education industry [43]. They determined that AR can enhance learning achievements and motivate students. Researchers show the growth in online education and distant-learning that uses IVE [44]. Researchers developed an AR-based teaching system [45]. They showed that teaching using their AR-based application increases student motivation and improves the innovation and creativity of the design outputs in a design course. Researchers developed a VR-based tool that is proved to be a reliable and effective solution to the challenges faced by students in visualizing $3 \mathrm{D}$ structures [46]. It allows students to visualize and review various designs through a VR environment. 
The efficiency and usefulness of the tool were assessed by surveys, group interviews, and in-class exercises. The results showed that subjects had a far better understanding of concepts when using a VR interface.

\section{2. $A R / V R$ in $A E C$}

Usage of AR/VR technologies in other fields such as healthcare, education, and retail has shown to be useful for improving human behavior, student learning enhancement, and increasing revenues in retailing. The other fields are growing in this area and also, recently, AEC has grown too, but more in some specific areas and not across the entire industry mainly because of lack of budget in the industry, and as a result, the AEC industry has not adopted these tools, but it is possible to improve budget and enhance scheduling if AR/VR are effectively used.

Utilization of IVEs in an engaging experience for end-users in the project design process, and combining IVEs sense of presence and BIM models can enhance the opportunity to evaluate different alternative design options in a time and cost-effective approach.

The AEC industry has many potential use cases for utilizing AR/VR technologies such as safety training, improving BIM visualization and communication, BIM-based immersive tools, energy savings, and understanding end-users (occupants) preferences. Researchers performed a case study on personalized safety training in an IVE in order to achieve more efficient safety training with better results [47]. Researchers conducted a research study to evaluate the long-term effect of VR safety training in comparison to traditional approaches [48]. They performed an experiment with two groups of 30 respondents. They gave a VR-based training to the first group while the second group went through the traditional safety training program. The results of the study indicated that the VR-based safety training program is significantly more effective than the traditional approach in both the short term and long term. Researchers developed an online VR framework that enables workers to perform dialogic learning, role-playing, and social interaction to provide better safety and health education for the workers [49]. They concluded that the platform effectively improves health and safety education. Researchers developed a training strategy that simulated construction accidents in the VR environment to demonstrate accident causation and the importance of thorough hazard recognition and proper risk perception [50]. After training, the workers were able to identify more hazards, perceive them with a higher level of risk, and were able to use effective management strategies to control the hazards concluding that VR environments provide a high degree of realism, which improves training outcomes.

Researchers developed a framework for cost estimation in construction using VR technology. They used a real-time VR model that can give the stakeholders and the users the ability to change the material of the walls, floors, and other parts, and the model provides them the price impact in real-time [51]. Linking cost estimation to VR can be beneficial to the AEC industry, especially to estimators. Researchers introduced a cloud-based VR system called CoVR to improve communication among stakeholders in a construction project [15]. CoVR is able to import BIM data and visualize it in a multiuser interactive virtual environment. This platform enables remote stakeholders to have social and face-to-face interactions with others. The researchers conducted a survey on CoVR and the results demonstrated that CoVR can enhance communication. Researchers developed a MAR application that can augment BIM models on top of the real-world building [52]. This application has the potentials to help technicians to optimize and visualize their model and data promptly in an AR application.

In addition, researchers utilized VR to improve construction safety. Researchers have developed a safety training program using VR and generated personalized feedback for the participants to improve safety training outcomes $[53,54]$. The outcomes indicate that safety training programs that utilize VR technology provide high fidelity simulations for the workers. In general, VR can present better spatial perception than conventional visualization methods such as 2D screens [51]. Consequently, VR technology can help in improving the quality of training [17]. Researchers have stated that visualization technologies such as VR can efficiently improve current safety training programs and improve workers' hazard recognition skills [32]. Researchers have proposed a platform that utilizes 
360-degree panoramas recorded videos from reality and used the videos in VR for construction safety training, and the outcome indicates that the proposed platform will significantly improve workers' hazard identification skills [55].

Researchers have presented a pilot study that utilizes VR. The presented VR solution can enhance the safety and occupational health of workers [38]. In this study, safety experts trained the workers and tested different motion tracking systems, HMD, joysticks as input methods, and training scenarios and compared the results. The results illustrated that VR technology could be an effective platform for safety training and substitute on-site training. Researchers assessed the VR safety training systems and illustrated that these systems have a significant positive learning experience [25]. In addition, researchers in the AEC proposed the idea of fusing EEG and VR technologies to assess humans' behavior in virtually-designed areas [56,57]. Overall, research suggests that VR can be used as one of the useful tools for improving current safety training programs.

Some researchers used IVE to develop an interactive training environment for workers, technicians, and engineers. Researchers introduced a VR-based interactive environment that enables a user to interact with triggered problems on a construction site and make decisions [58]. They can see how their decisions affect project cost and schedule. The respondents of this study were interested in the tools and believed that VR provided better interaction and improved decision making. Researchers developed a virtual prototyping platform to improve crane safety. In this platform, a lift crew, consisting of a planner, rigger, signalman, and operators, virtually perform lifting operations [59]. The results indicate that this tool can improve the operator's confidence and safety. Researchers developed a VR platform that can simulate the heavy mobile crane lift in modular construction [60]. This platform enables the lift crew and engineers to simulate the lift in an IVE and evaluate different options in real-time. This platform can simplify the heavy lift planning, improve the lift crew's performance on the construction site, and reduce human error.

Furthermore, some studies used IVE for improving the degree of presence in lighting condition assessment and energy management [61,62]. Researchers developed a design approach combining VR and design with an intent concept that can help in closing the energy performance gap caused by occupants' behavior [35]. The results indicate that the developed framework can help designers detect design patterns that can predict actual occupant behaviors. Researchers conducted an experiment to compare the respondents' sense of presence in a VR environment versus a real environment [63]. A realistic model of a room with different lighting options was created. The respondents selected similar options in VR versus a real room. The results showed that VR is effective in obtaining user feedback. The feedback can improve the end-user satisfaction rate and performance in design [64]. In another IVE study, researchers evaluated how psychological factors such as defaults and personality traits may influence occupant's lighting and shading interactions; through collecting data from over 150 participants, they concluded that without any additional cost, defaults can be used to significantly reduce the lighting electricity consumption in commercial buildings [65].

\section{Method}

The hypotheses in this paper are: (1) age has a direct effect in adoption and utilization of AR/VR technologies; (2) within the AEC sectors, residential and commercial projects are expected to utilize AR/VR more than other sectors; and (3) for a better utilization of VR, construction companies need to have a full adoption of BIM. Through a set of comprehensive surveys, the authors tested these hypotheses. Furthermore, this paper aims to understand the potential cost and time savings and find opportunities for AR/VR developments in order to improve communication and visualization among different stakeholders. This study was carried out in accordance with the recommendations of the Institutional Review Board at the University of Virginia. The protocol was approved by the Institutional Review Board at the University of Virginia. All subjects gave written informed consent in accordance with the Declaration of Helsinki. 
Since the implementation of AR/VR technologies is still relatively new within the AEC industry, there is not much empirical data on these topics. In order to gather some information regarding the trends and utilization of AR/VR tools and test our three hypotheses, the authors came up with a number of research methods. First, the authors designed a detailed online questionnaire. The detailed questionnaire was reviewed by three BIM specialists as well as three researchers within the field of construction engineering and management to ensure questions are clear and not misleading. The authors designed the questionnaire in a way to analyze the growth of these technologies by collecting responses at two different time periods. Finally, through the survey results, the authors identified some of the industry trends from 2017 to 2018 and provide some information about the industry's visions on the future of AR/VR technologies.

The questionnaire is formulated to gather information about the AEC industry's adoption of AR/VR technologies from 2017 to 2018. Moreover, the questionnaire investigated the opportunities for AR/VR technologies to improve stakeholders' communication and identify experts' predicted return on investment. The online surveys were hosted on https://new.qualtrics.com/. Qualtrics enabled the authors to keep a record of the computer address from which the survey was completed using internet protocol (IP) and assign an identification number (ID) to the user's IP. Qualtrics excluded duplicated data by checking respondents' profiles, IPs, IDs, and entries from the database for analyzing survey results. The excluded responses were mainly from the respondents who did not complete the survey so that the authors could not accredit their credibility for the goals of this research.

As a first step, a set of 27 survey questions were designed to target a range of AEC professionals, such as engineers, designers, researchers, managers, and owners. The survey questions were divided into five sections: (1) general information, (2) company-related information, (3) BIM knowledge, (4) AR/VR related information, and (5) visions for the future of AR/VR within the AEC industry. The first three sections capture the background and experience of the respondents. Then, AR/VR is evaluated in the next two sections. Table 1 (description of target areas and objectives with respect to different parts of the survey) describes the main sections, gathered data, and the objective of each section in more detail. It also shows the main constructs. In this study, the measures are the asked questions from the participants.

Table 1. Description of target areas and objectives with respect to different parts of the survey.

\begin{tabular}{|c|c|c|c|}
\hline General Section & Section Name & Gathered Data & Objectives \\
\hline \multirow{3}{*}{$\begin{array}{l}\text { Background and } \\
\text { Experience }\end{array}$} & General information & $\begin{array}{l}\text { Age, gender, occupation, } \\
\text { and professional } \\
\text { experience }\end{array}$ & $\begin{array}{l}\text { Determine how respondents } \\
\text { in different positions } \\
\text { envision the future of AR/VR }\end{array}$ \\
\hline & $\begin{array}{l}\text { Company-related } \\
\text { information }\end{array}$ & $\begin{array}{l}\text { Companies size, } \\
\text { turnovers, and } \\
\text { employees number }\end{array}$ & $\begin{array}{l}\text { Assess how companies with } \\
\text { different sizes envision the } \\
\text { future of AR/VR }\end{array}$ \\
\hline & $\begin{array}{l}\text { BIM knowledge and } \\
\text { experience }\end{array}$ & $\begin{array}{l}\text { BIM experience and used } \\
\text { BIM tools }\end{array}$ & $\begin{array}{c}\text { Evaluate how respondents } \\
\text { with different BIM } \\
\text { knowledge envision the } \\
\text { future of AR/VR }\end{array}$ \\
\hline \multirow{2}{*}{ AR/VR Evaluation } & $\begin{array}{l}\text { AR/VR knowledge and } \\
\text { experience }\end{array}$ & $\begin{array}{l}\text { AR/VR experience and } \\
\text { used AR/VR tools }\end{array}$ & Identify the industry trends \\
\hline & $\begin{array}{l}\text { Visions for the future of } \\
\text { AR/VR }\end{array}$ & $\begin{array}{l}\text { Opportunities of AR/VR } \\
\text { in the AEC industry }\end{array}$ & $\begin{array}{c}\text { Trends for the future } \\
\text { adoption and utilization of } \\
\text { AR/VR in AEC }\end{array}$ \\
\hline
\end{tabular}

The first and second rounds of the survey had 94 and 64 respondents, respectively. The surveys were distributed directly among professionals within the AEC industry and also through the Construction Management Association of America (CMAA) organization. CMAA was chosen since it has a great combination of 16000 members in the AEC industry from both public and private sectors across the 
USA. CMAA expert members are from different parties such as owners, architects and designers, general contractors, and construction managers. The authors conducted the first round of the survey in March through May 2017 and the second round in February through March 2018. The surveys were distributed in two rounds to measure the impact and growth of AR/VR within the AEC industry and identify trends and visions for future adoption of these technologies.

The first section of the survey attempts to identify the general information of the respondents, such as age, gender, occupation, and professional experience. In the next section, the respondents answer several questions about their companies, such as geographical location, size, and type of projects (e.g., residential commercial, institutional, etc.). The third section examines the respondents' competency in BIM technology and applications (i.e., quality control, progress monitoring).

In the next two sections, the survey results assessing AR/VR utilization in the AEC industry, as well as the future opportunities for AR/VR applications, are presented. First, the respondents are asked what types of AR/VR devices they have used and how many AR/VR experts they have in their companies. Through these questions, the authors were able to evaluate the respondents' familiarity with AR/VR tools and their companies' effort in integrating these technologies with on-going and future projects. In the last section, the respondents were asked to answer a few questions about their vision for the future integration of AR/VR technologies within the AEC industry. The questions in this section were designed in a way that demonstrates AR/VR potentials for future developments. For example, the respondents were asked to identify the sectors (i.e., education and healthcare facilities) and the project size that can best leverage AR/VR technology. The last section evaluated the visions for cost and time saving through integrating AR/VR technologies in construction projects. The last two questions evaluate how the respondents predicted the increase in end-user satisfaction when AR/VR technology is used and their limitations in AEC-related applications. By understanding the potential and maturity of AR/VR technologies, industry leaders can better understand the potential use-case of these tools. The identified industry trends can help industry leaders make better investment decisions on these technologies.

\section{Survey Results}

In this section, the survey responses are analyzed to (1) understand the current state and growth of AR/VR in the AEC industry over the past year, (2) identify opportunities of AR/VR development in improving communication and visualization among different parties, and (3) understand the benefits, that are foreseen by AEC practitioners of adopting AR/VR technologies.

In order to account for participant privacy, the surveys did not ask for any personal information such as name, company name, etc., from the participants. To detect whether participants took part in both rounds, the authors added a question to the second survey asking the participants whether they had participated in the same survey study previously. The results for this question demonstrated that none of the participants in the second round of survey participated in the first round. We did not have participants from the same company or institution. The survey results are analyzed as follows to understand these trends.

\subsection{General Respondent Information}

Overall, in both surveys, $71 \%$ ( $67 \%$ and $77 \%$, respectively, in each survey) of the respondents were male and $29 \%$ were female (33\% and 23\%, respectively, in each survey). Respondent's age ranged from 25 to 60 with an average of 32 overall in both surveys. Approximately, $70 \%$ of the respondents (78 out of 114 respondents who were willing to share their age) were 30 years old or younger. Respondents were also asked about their roles in the AEC industry. The survey categorized the respondents in four groups of engineer and designer ( $49 \%$ and $51 \%$, respectively in each survey), researcher $(21 \%$ and $32 \%$, respectively in each survey), manager (29\% and $17 \%$, respectively in each survey), and owner (1\% and $0 \%$, respectively, in each survey). Professional experience is another important indicator of the expertise of the respondents. Most of the respondents with expertise in BIM and AR/VR technologies 
were relatively young. Overall, in both surveys, approximately $75 \%$ of the respondents indicated that they had 10 years or less of professional experience in the AEC industry. Table 2 shows the number of years the respondents have spent at their current companies and presents how many years they have worked in the AEC industry in parenthesis.

Table 2. Participants experience in current company (Architecture, Engineering, and Construction (AEC) industry).

\begin{tabular}{cccc}
\hline & $\mathbf{2 0 1 7}$ & $\mathbf{2 0 1 8}$ & Overall in AEC \\
\hline Less than a year & $27 \%(13 \%)$ & $33 \%(13 \%)$ & $29 \%(13 \%)$ \\
$1-5$ years & $57 \%(41 \%)$ & $56 \%(40 \%)$ & $57 \%(40 \%)$ \\
$6-10$ years & $8 \%(20 \%)$ & $4 \%(27 \%)$ & $7 \%(23 \%)$ \\
More than 10 years & $7 \%(25 \%)$ & $6 \%(21 \%)$ & $7 \%(24 \%)$ \\
\hline
\end{tabular}

\subsection{Company-Related Information}

Among the respondents with AR/VR experience, California had the highest rate, 51\%, of participation (22 out of 43 respondents with a high level of AR/VR experience). After that Illinois was the second-highest rate, $12 \%$ (5 out of 43 respondents with a high level of AR/VR experience). The third state was New York with 9\% (4 out of 43 respondents with a high level of AR/VR experience) (Figure 1 demonstrates the heatmap of the distribution of the respondents across the US).

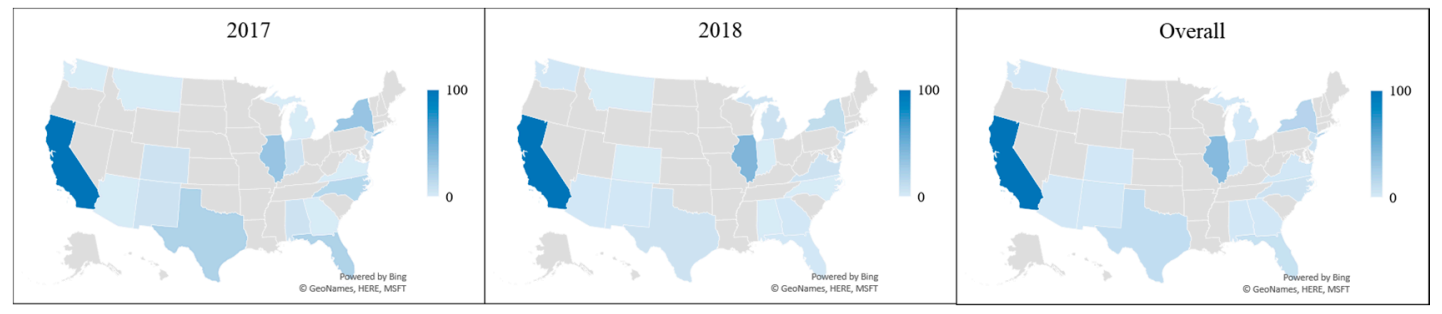

Figure 1. Geographical information of the respondents in 2017, 2018, and overall.

The numbers of employees and project values can be used to infer the size of a company, which can help determine how companies with different sizes envision the future of the AR/VR technologies. As the results demonstrate, $17 \%$ of overall respondents were currently working at companies with more than 5000 employees (14\% in 2017 analysis and 21\% in 2018 analysis), 26\% were in 1000-5000 employees company (23\% 2017 analysis and 32\% 2018 analysis), 21\% were in 200-1000 employees company (23\% 2017 analysis and 18\% 2018 analysis), and 36\% were less than 200 employees company (40\% 2017 analysis and 29\% 2018 analysis). Participants working for the AEC industry (excluding researchers) were also asked to identify what type of project(s) they were mainly involved with based on the average project cost (i.e., $>\$ 100$ million, $\$ 10-\$ 50$ million, etc.). Approximately $45 \%$ of participants were working on projects $>\$ 10$ million in value and $50 \%$ on projects less than $\$ 5$ million. It is important to note that participants had the option of choosing more than one answer to this question.

The respondents had a wide variety of project types, which were divided into five different sectors, including residential, commercial, institutional, transportation, and industrial (Table 3). Approximately $60 \%$ of the participants indicated they are involved with vertical projects and $15 \%$ working on horizontal projects. Combining the results from this question and other questions (i.e., the number of VR experts) can demonstrate the growth and adoption of AR/VR technologies in these sectors. 
Table 3. Building Information Modeling (BIM) trends between 2017 and 2018.

\begin{tabular}{|c|c|c|c|c|}
\hline Section & Option & 2017 & 2018 & Overall \\
\hline \multirow{6}{*}{ Companies project types } & Residential & $21 \%$ & $27 \%$ & $23 \%$ \\
\hline & Commercial & $27 \%$ & $23 \%$ & $25 \%$ \\
\hline & Institutional & $23 \%$ & $19 \%$ & $21 \%$ \\
\hline & Transportation & $15 \%$ & $16 \%$ & $16 \%$ \\
\hline & Industrial & $9 \%$ & $12 \%$ & $10 \%$ \\
\hline & Other & $5 \%$ & $4 \%$ & $5 \%$ \\
\hline \multirow{4}{*}{$\begin{array}{l}\text { The frequency of BIM } \\
\text { tool usage }\end{array}$} & Never use any BIM models & $23 \%$ & $19 \%$ & $21 \%$ \\
\hline & Monthly basis & $14 \%$ & $19 \%$ & $16 \%$ \\
\hline & Weekly basis & $27 \%$ & $23 \%$ & $26 \%$ \\
\hline & Daily basis & $36 \%$ & $38 \%$ & $37 \%$ \\
\hline \multirow{5}{*}{$\begin{array}{l}\text { Familiarity with BIM tools } \\
\text { based on years of experience }\end{array}$} & Never used them before & $14 \%$ & $13 \%$ & $14 \%$ \\
\hline & Less than a year & $12 \%$ & $13 \%$ & $12 \%$ \\
\hline & $1-3$ years & $35 \%$ & $41 \%$ & $37 \%$ \\
\hline & $3-6$ years & $18 \%$ & $11 \%$ & $15 \%$ \\
\hline & More than 6 years & $21 \%$ & $22 \%$ & $22 \%$ \\
\hline \multirow{8}{*}{ Main sections for BIM usage } & Model validation & $20 \%$ & $20 \%$ & $20 \%$ \\
\hline & Clash detection & $20 \%$ & $18 \%$ & $19 \%$ \\
\hline & Visualization and trade coordination & $23 \%$ & $18 \%$ & $20 \%$ \\
\hline & Transportation and logistics & $5 \%$ & $11 \%$ & $7 \%$ \\
\hline & Model-based cost estimation & $11 \%$ & $12 \%$ & $11 \%$ \\
\hline & 4D simulation (3D + schedule) & $11 \%$ & $15 \%$ & $13 \%$ \\
\hline & Energy simulations and lighting analysis & $5 \%$ & $3 \%$ & $4 \%$ \\
\hline & Facility management purposes & $6 \%$ & $3 \%$ & $5 \%$ \\
\hline
\end{tabular}

\subsection{BIM Knowledge and Experience}

To assess BIM knowledge of the respondents, several questions related to BIM utilization were asked. The first question was about the BIM usage level. More than $75 \%$ of the respondents answered that they use BIM tools at least once a month. In addition, more than $90 \%$ of engineers use BIM on a monthly basis. The high usage of BIM among engineers demonstrates the importance of this technology for the industry. Table 3 shows the BIM usage rate for the respondents.

The second question in this section was about the experience of the respondents with BIM tools. Of the respondents, $86 \%$ expressed that they have had some experience with BIM tools and only $14 \%$ of the respondents have never used any BIM tool at all. Among the respondents with no BIM experience, $63 \%$ were engineers, $16 \%$ were managers, and $22 \%$ were researchers. The results show, although AEC research strongly recommends BIM, still many engineers have not used and were never trained to use any BIM tools. Table 3 presents the respondents' experience with BIM tools.

The last question in this section was about applications of BIM used by the respondents. The top three applications of BIM were clash detection, model validation, and visualization and trade coordination. Using BIM for facility management purposes, energy and light simulations, transportation, and cost estimation were the least options that were chosen by the respondents. Although there were several BIM tools available in the aforementioned areas, the adoptions of BIM tools in these areas were significantly lower as shown in Table 3. However, the deficiency of BIM in these areas means more room for potential applications of AR/VR technologies.

The results of this section suggest that the frequency of using BIM did not change significantly over the past year. Additionally, on average, the majority of respondents indicated they use BIM solutions and applications on a daily basis. This result is aligned with BIM global reports such as NBS BIM which indicates over $99 \%$ of the industry is aware of BIM and more than $74 \%$ of the industry currently adopting BIM in their projects [11]. It is important to note that BIM solutions are required to develop accurate and interactive AR/VR environments. 


\subsection{AR/VR Knowledge and Experience}

This section evaluates the adoption of AR/VR technologies in the AEC industry from 2017 to 2018 by comparing the result of the first round of the survey with the result of the second round. Table 4 represents the important questions and options that were selected by the experts. In each survey, the respondents were asked about their familiarity with AR/VR equipment and whether they have used any related tools. As shown in Table 4, there has been a significant increase in respondents' familiarity and use of AR/VR tools from the first survey to the second survey. This growth indicates that companies and AEC professionals are becoming more familiar and interested in adopting AR/VR tools.

Table 4. Augmented Reality (AR)/Virtual Reality (VR) trends between 2017 and 2018.

\begin{tabular}{|c|c|c|c|c|c|}
\hline Section & Option & 2017 & 2018 & Overall & Difference \\
\hline \multirow{3}{*}{ Usage of AR/VR } & No, not at all & $32 \%$ & $11 \%$ & $25 \%$ & $-21 \%$ \\
\hline & $\begin{array}{c}\text { No, but I have seen } \\
\text { demos and videos }\end{array}$ & $37 \%$ & $33 \%$ & $35 \%$ & $-4 \%$ \\
\hline & Yes & $31 \%$ & $57 \%$ & $40 \%$ & $26 \%$ \\
\hline \multirow{5}{*}{$\begin{array}{l}\text { Understanding and expertise in } \\
\text { AR/VR tools }\end{array}$} & Hardly at All & $4 \%$ & $4 \%$ & $4 \%$ & $0 \%$ \\
\hline & Not Very Well & $15 \%$ & $8 \%$ & $12 \%$ & $-7 \%$ \\
\hline & Average & $38 \%$ & $28 \%$ & $33 \%$ & $-10 \%$ \\
\hline & Very Well & $27 \%$ & $40 \%$ & $33 \%$ & $13 \%$ \\
\hline & Extremely Well & $15 \%$ & $20 \%$ & $18 \%$ & $5 \%$ \\
\hline \multirow{6}{*}{$\begin{array}{c}\text { Number of AR/VR experts in } \\
\text { the company }\end{array}$} & Not sure & $29 \%$ & $19 \%$ & $25 \%$ & $-10 \%$ \\
\hline & 1-3 people & $38 \%$ & $35 \%$ & $37 \%$ & $-3 \%$ \\
\hline & 3-6 people & $24 \%$ & $19 \%$ & $22 \%$ & $-5 \%$ \\
\hline & 6-10 people & $5 \%$ & $14 \%$ & $8 \%$ & $8 \%$ \\
\hline & 10-25 people & $2 \%$ & $5 \%$ & $3 \%$ & $4 \%$ \\
\hline & $25+$ people & $2 \%$ & $8 \%$ & $4 \%$ & $6 \%$ \\
\hline \multirow{5}{*}{$\begin{array}{l}\text { AR/VR usage on majority of the } \\
\text { projects within } 10 \text { years }\end{array}$} & Definitely not & $2 \%$ & $0 \%$ & $2 \%$ & $-2 \%$ \\
\hline & Probably not & $15 \%$ & $0 \%$ & $9 \%$ & $-15 \%$ \\
\hline & Might or might not & $18 \%$ & $22 \%$ & $20 \%$ & $4 \%$ \\
\hline & Probably yes & $40 \%$ & $38 \%$ & $39 \%$ & $-2 \%$ \\
\hline & Definitely yes & $24 \%$ & $40 \%$ & $30 \%$ & $16 \%$ \\
\hline \multirow{5}{*}{$\begin{array}{l}\text { Increase in end-users satisfaction } \\
\text { rate by integrating } A R / V R\end{array}$} & Significantly & $49 \%$ & $61 \%$ & $54 \%$ & $12 \%$ \\
\hline & Somewhat & $33 \%$ & $34 \%$ & $34 \%$ & $1 \%$ \\
\hline & Neutral & $5 \%$ & $5 \%$ & $5 \%$ & $-1 \%$ \\
\hline & Not much & $9 \%$ & $0 \%$ & $6 \%$ & $-9 \%$ \\
\hline & Not at all & $3 \%$ & $0 \%$ & $2 \%$ & $-3 \%$ \\
\hline
\end{tabular}

Table 4 indicates respondents' self-reported expertise and level of understanding of AR/VR technologies. Additionally, it further represents how these tools are being or envisioned to be used within the AEC industry.

The collected data shows a 5\% and 13\% increase in the "extremely well" and "very well" expertise and understanding categories, respectively, between the two surveys. This growth indicates there has been a significant increase in the integration of AR/VR tools within AEC projects, where industry professionals are more exposed to these tools and have a better understanding of their capabilities. 
Respondents were also asked about which VR devices they are more familiar with and recommend to be used. The results of both surveys indicate that respondents are most familiar with and recommend Oculus Rift (approximately 45\%), followed by HTC Vive, Samsung Gear, and Microsoft HoloLens. Comparing the results of first and second surveys, respondents' significantly increased recommending the use of HTC Vive as well as a slight increase in Microsoft HoloLens. Consequently, recommendations for Oculus Rift and Samsung Gear marginally decreased between the two surveys.

The last question in this section is about the number of AR/VR experts in each respondents company. As it is shown in Table 4, more employees are becoming familiar with AR/VR tools among the respondents' companies. This result may also indicate that the industry is adopting AR/VR technologies at a faster pace.

\subsection{Visions of the Future AR/VR}

This section was designed to determine the opportunities of AR/VR in the AEC industry. Respondents were asked to predict whether AR/VR will be used on all or a majority of the projects within the next 5 to 10 years. More than $70 \%$ of all respondents chose "probably yes" or "definitely yes," indicating a significant increase in the adoption of AR/VR technologies. In addition, over the past year, the percentage of "definitely yes" and "probably yes" increased by $14 \%$, indicating a rapid and positive change in the industry trend. Table 4 presents respondents' predictions on the AR/VR usage in the AEC industry for the next 5 to 10 years.

The respondents were also asked to identify the sector that has the highest potential for the growth in VR utilization. Most of the sectors had the same rate, but the result shows that the healthcare facilities with $23 \%$ and commercial buildings with $21 \%$ are more promising.

The last question of this section asked for an optimal project size in which AR/VR can be most beneficial. Large projects had the highest response, showing that large and mega projects can make the most out of AR/VR technologies (approximately $70 \%$ on both surveys) compared to small (10\% and $5 \%$ on each survey, respectively) and medium projects ( $20 \%$ and $25 \%$ on each survey, respectively).

In the last section of the survey, the main opportunities and limitations of AR/VR were questioned. Respondents were asked to estimate the increase in end-user (i.e., owners, contractors, and occupants) satisfaction. Approximately $90 \%$ agreed that AR/VR can either "significantly" or "somewhat" improve the customer satisfaction rate. Furthermore, there was a growth in positive answers, from the first round of the survey to the second, as shown in Table 4.

The respondents were also asked to identify the limitations of AR/VR technologies; $21 \%$ indicated "lack of budget" as a limiting factor, 17\% indicated upper management's lack of understanding of these technologies, and $17 \%$ mentioned design teams' lack of knowledge as the main limitation for AR/VR utilization. Table 4 presents these results. Addressing these limitations can further increase the adoption of AR/VR technologies in the AEC industry.

In the last question of this section, the respondents were asked for their estimate of time and cost savings (if any) in different phases of a project by adopting AR/VR technologies. The respondents' options for this question were based on the savings in terms of the project cost percentage. Approximately $55 \%$ of the respondents predicted more than $1 \%$ savings can be achieved by integrating VR/AR tools during the design and construction phases. Over $60 \%$ predicted savings of $1 \%$ during the operation phase. Table 5 shows the result in the design and construction phases and the operation phase in parenthesis. As this table shows, a significantly higher number of respondents believe cost savings will be within $0.5 \%$ to $1 \%$. However, in 2018 , a smaller number of participants envisioned the cost savings to be "noticeably effective". 
Table 5. Cost and time savings by utilizing AR/VR during the design and construction (operation) phase.

\begin{tabular}{ccccc}
\hline & $\mathbf{2 0 1 7}$ & $\mathbf{2 0 1 8}$ & Overall & Difference \\
\hline I am not sure & $21 \%(20 \%)$ & $11 \%(16 \%)$ & $17 \%(18 \%)$ & $-9 \%(-4 \%)$ \\
Not much $(<0.5 \%$ in saving) & $9 \%(6 \%)$ & $7 \%(7 \%)$ & $8 \%(6 \%)$ & $-2 \%(1 \%)$ \\
Slightly effective $(0.5 \%-1 \%$ saving) & $16 \%(21 \%)$ & $32 \%(25 \%)$ & $21 \%(23 \%)$ & $16 \%(4 \%)$ \\
Noticeably be effective (1\%-3\%) & $44 \%(35 \%)$ & $32 \%(32 \%)$ & $40 \%(34 \%)$ & $-12 \%(-3 \%)$ \\
$\begin{array}{c}\text { More effective than BIM } \\
\text { technologies }(>5 \%)\end{array}$ & $10 \%(18 \%)$ & $18 \%(20 \%)$ & $13 \%(19 \%)$ & $8 \%(2 \%)$ \\
\hline
\end{tabular}

\section{Discussion and Analysis of Survey Findings}

This section further discusses the survey results and how the results were analyzed. The main software used to perform statistical analyses were IBM SPSS and Microsoft Excel.

To measure the growth of confidence level of the respondents, the respondents' prediction on whether or not AR/VR technologies will be used on the majority of the projects within the next 5 to 10 years was analyzed. The result from unpaired $t$-test indicates that there was a significant difference in the scores (definitely not $=0$, probably not $=1$, might or might not $=2$, probably yes $=3$, definitely yes $=4)$ of this question for the first survey $(M=2.63, S D=1.13)$ and second survey $(M=3.20$, $S D=0.76) ; p=0.001$. These results suggest that the confidence level of respondents about the future of AR/VR technologies in the second survey is significantly higher than respondents in the first survey. This means that the AEC experts are paying more attention to the AR/VR technologies. The increase in the number of employees with some level of expertise in AR/VR technologies between the two surveys also supports this finding.

In addition, although it seems that respondents who are relatively younger (i.e., less than 35 years old) believe that AR/VR technologies will be used on the majority of the projects within the next 5 to 10 years, the survey results indicate that the older generations are more confident about the future of these technologies. An unpaired $t$-test was conducted to compare younger (younger than 35 years old) and older (older than 35 years old) generations' ideas about the future of AR/VR. There was a significant difference in the scores for younger generations $(M=2.86, S D=1.01)$ and older generations $(M=3.29, S D=0.77) ; p=0.025$. These results suggest that older generations' positive beliefs about the future of AR/VR technologies are significantly higher than younger generations. Such findings may indicate that the older generation has more experience with the recent changes and advancements of technologies within the AEC industry (i.e., BIM) and they believe AR/VR tools can provide significant benefits to the industry.

Moreover, the increase in the number of employees with some level of AR/VR expertise indicates the growth in the utilization of such technologies. Performing unpaired $t$-test on survey data shows that there was a significant difference in the number of employees with some levels of AR/VR expertise between the first survey $(M=1.24, S D=2.99)$ and the second survey $(M=3.55, S D=0.65) ; p=0.015$. These results suggest that there was a significant increase in employees becoming familiar with these technologies over the past year. Furthermore, the results show that although familiarity with AR/VR technologies did not change in the education field over the past year. However, there was a decrease in industry-related responses. This finding indicates that there is still a large gap in the industry's familiarity with AR/VR compared to academia. As a result, the industry needs to be educated and understand use cases to become familiar with AR/VR technologies.

In addition, the authors used unpaired $t$-test to identify the growth in employees expertise and there was a significant difference in the scores (hardly at all $=0$, not very well $=1$, average $=2$, very well $=3$, extremely well $=4)$ of AR/VR for the first survey $(M=0.64, S D=1.18)$ and the second survey $(M=1.27, S D=1.51) ; p=0.009$. These results demonstrate that $A R / V R$ related expertise of the respondents in the second survey significantly improved compared to the first survey.

By dividing the company size into four categories (the same sizes in the surveys), companies with less than 200 employees (small companies) showed great interest in employing AR/VR experts. 
The AR/VR expert employment rate increased by 0.75 persons per (approximately one person) in a smaller-sized company from 2017 to 2018. This indicates, due to the lower overhead rate compared to larger companies, they intend to focus on new technologies and expertise to maximize their profit. However, the respondents expected that large and mega-companies (companies with more than 2000 employees) would benefit the most from AR/VR technologies. Performing an independent $t$-test on AR/VR expert employment rate on mega-companies (companies with more than 5000 employees) shows a marginally significant improvement over the past year with 0.071 significance level. This finding suggests that mega-companies are beginning to invest more in AR/VR technologies.

To show the prediction of AEC experts about the potential savings of AR/VR, the authors performed an unpaired $t$-test on the results from the last two questions of the survey. Unpaired $t$-test demonstrates that there was a significant difference in the potential cost and time savings score (percentage of entire project value) in design, construction, and operation by utilizing AR/VR. The results for the first survey $(M=3.21, S D=6.7)$ and the second survey $(M=4.17, S D=10.97), p=0.049$ suggest that respondents' predictions about savings through AR/VR significantly increased in the second survey. Unpaired $t$-test shows that there was a significant difference in the potential predicted savings scores of AR/VR from respondents with no BIM experience $(M=2.90, S D=2.94)$ and BIM experts $(M=3.80, S D=2.71)$; $p=0.033$. These results suggest that respondents with higher BIM experience predict significantly more savings through AR/VR compared to respondents with no BIM experience.

The results of the surveys indicate that the number of AR/VR experts increased by $82 \%$ and $110 \%$ in the institutional and transportation sectors, respectively, over the past year. In line with the authors' hypothesis, residential and commercial sectors accounted for the highest number of AR/VR experts with an average of 5.34 and $5.23 \mathrm{AR} / \mathrm{VR}$ experts, respectively, and the industrial sector did not show an increase as much as other sectors. These findings are well aligned with sectors that were predicted to have the most benefits from utilizing AR/VR technologies. In addition, a Chi-squared test suggests that there was a marginal increase in the vision for the benefits of the healthcare section $(p=0.066)$. This finding is consonant with improvements in the number of AR/VR experts in the institutional sector. Therefore, the finding also suggests that there will be a growth in healthcare within the institutional sector in the future.

Using the survey results, lack of budget, lack of understanding of upper management about AR/VR technologies, and lack of knowledge of design teams were the top three reported limitations for utilizing AR/VR technologies. It is important to note that all the limiting factors decreased over the past year, except for "lack of upper management knowledge" which was increased by $7 \%$. This shows that upper management might need to become more educated and aware of the use cases and benefits of AR/VR technologies.

Table 6 depicts the main results from the $t$-test analysis on the survey results. Furthermore, the data does not show any more significant results by analyzing, gender, occupation, and company location. Table 6 shows the main extracted hypotheses from the survey.

Table 6. $T$-test analysis results on surveys with a significance level.

\begin{tabular}{lc}
\hline \multicolumn{1}{c}{ Significance Factor } & P-Value \\
\hline Confidence level about the future of AR/VR technologies significantly increased over the & 0.001 \\
past year & 0.025 \\
Older generations are significantly more confident about the future of these technologies & 0.015 \\
The number of employees with AR/VR expertise improved significantly over the past year & 0.009 \\
Employees expertise in AR/VR significantly increased over the past year & 0.070 \\
Number of AR/VR experts is significantly different for the small companies and the & 0.049 \\
big companies & 0.033 \\
Cost and time savings in design, construction, and operation by utilizing AR/VR & \\
significantly improved over the past year & \\
Savings by utilizing AR/VR is predicted significantly different from respondents with no & \\
\hline BIM experience vs. BIM experts &
\end{tabular}




\section{Conclusions and Future Vision}

Although the AEC industry is far behind other industries such as healthcare and retail in adopting AR/VR technologies in the research literature, the results of this study showed that the AEC industry is changing its previous path towards utilizing these technologies. This paper presents two rounds of a survey that were conducted at two different time periods with about a year part. The results were analyzed to assess the current state, growth, and saving opportunities for AR/VR technologies in the AEC industry. The results of the surveys show that industry experts foresee strong growth in the use of AR/VR technologies over the next 5 to 10 years. Furthermore, the results show a significant increase in AR/VR utilization in the AEC industry over the past year and potential opportunities.

This paper demonstrated that (1) older generations are significantly more confident about the future of AR/VR technologies and they see more benefits in utilization of such technologies; (2) furthermore, the research results indicate that residential and commercial projects were the top sections that utilized AR/VR technologies; and finally (3) the industry is growing significantly in adoption of these technologies.

The surveys show some inherent limitations in the AEC industry adopting new AR/VR technologies such as the "lack of budget," "upper management's lack of understanding of these technologies," and "design teams' lack of knowledge." Due to the lower profit margins on construction projects, one major limiting factor that prevents the industry from adopting AR/VR technologies is the lack of availability of cost/benefit analysis. Owners and companies are not willing to invest their money without knowing the true costs and benefits (i.e., time and cost savings). Therefore, there is a need for empirical studies that assess the true costs of implementing these technologies and reduction in costs and time from design to operation and maintenance phases. With regards to the other two major limitations, the results show that within the one year period between the two surveys, the number of people within the respondents' companies that are familiar with AR/VR technologies has significantly increased; this may indicate that upper management and designers/engineers will become more familiar with the capabilities of these tools in the near future as these tools become more accessible to the general consumer.

Although this paper focuses on the benefits of both the AR and VR technologies, a more detailed study is required to better identify the benefits of each technology within the AEC industry. For instance, the survey results indicate that these technologies can be very effective for model visualization, validation, and clash detection, which are tasks related to pre-construction. However, with recent advancements in mobile augmented reality and machine learning, it is expected that AR head-mounted displays provide a better assistant to project teams during the construction phase (e.g., real-time safety feedback, progress monitoring) or facility managers during the operation phase (e.g., sensor data visualization, energy simulations) in comparison to VR tools.

Although respondents indicated that communication among software has improved within the past year, there still exist a number of limitations that can improve the capabilities of VR/AR technologies for AEC professionals. For instance, there is no robust approach for transferring all BIM information along with cost data into a VR platform. Importing BIM models into a 3D engine is a challenge because some of the building information (i.e., material library) might be lost during the export and import process. Moreover, connecting several VR headsets to enable a group meeting in a virtual space can enhance and improve communications among stakeholders. These problems have to be solved in order to convince the AEC industry to spend more money on the development and adoption in this area.

Author Contributions: M.N. and A.H. performed the Formal analysis; M.N. and K.H. developed the Methodology; V.B. and K.H. dealt with Supervision; Writing-M.N. wrote the original draft; Writing-review \& editing was performed by A.H., V.B., and K.H. All authors have read and agreed to the published version of the manuscript.

Funding: This work was partially funded under Versatile Test Reactor Program of the U.S. Department of Energy (DOE) by Battelle Energy Alliance, LLC (BEA), the Management and Operating Contractor of Idaho National Laboratory (INL) under Contract Number DE-AC07-05ID14517 with DOE. The United States Government has a non-exclusive, paid-up, irrevocable, world-wide license to publish and reproduce the published form of this work 
and allow others to do so, for United States Government purposes. Any opinions, findings, conclusions and/or recommendations expressed in this paper are those of the authors and do not reflect the views of the entities above.

Conflicts of Interest: The authors declare no conflict of interest.

\section{Abbreviations}

$\begin{array}{ll}\text { BIM } & \text { Building Information Modeling } \\ \text { VR } & \text { Virtual Reality } \\ \text { AR } & \text { Augmented Reality } \\ \text { AEC } & \text { Architecture, Engineering, and Construction } \\ \text { IVEs } & \text { Immersive Virtual Environments } \\ \text { IP } & \text { Internet Protocol } \\ \text { ID } & \text { Identification Number }\end{array}$

\section{References}

1. Wang, T. U.S. Construction Industry-Statistics \& Facts | Statista, Statista. 2017. Available online: https: //www.statista.com/topics/974/construction/ (accessed on 10 March 2020).

2. Changali, S.; Mohammad, A.; van Nieuwl, M. The Construction Productivity Imperative; McKinsey \& Company: New York, NY, USA, 2015.

3. Forcada, N.; Gangolells, M.; Casals, M.; Macarulla, M. Factors Affecting Rework Costs in Construction. J. Construct. Engin. Manag. 2017, 143. [CrossRef]

4. Fayek, A.R.; Dissanayake, M.; Campero, O. Measuring and Classifying Construction Field Rework: A Pilot Study. Available online: http://citeseerx.ist.psu.edu/viewdoc/download?doi=10.1.1.119.3806\&rep=rep1\& type $=$ pdf (accessed on 13 March 2020).

5. Gamil, Y.; Abdul Rahman, I. Identification of Causes and Effects of Poor Communication in Construction Industry: A Theoretical Review. Emerg. Sci. J. 2018, 1. [CrossRef]

6. Yalcinkaya, M.; Singh, V. Automation in Construction Patterns and trends in Building Information Modeling (BIM) research: A Latent Semantic Analysis. Autom. Constr. 2015, 59, 68-80. [CrossRef]

7. Volk, R.; Stengel, J.; Schultmann, F. Automation in Construction Building Information Modeling (BIM) for existing buildings-Literature review and future needs. Autom. Constr. 2014, 38, 109-127. [CrossRef]

8. Asadi, K.; Han, K. Real-Time Image-to-BIM Registration Using Perspective Alignment for Automated Construction Monitoring. In Proceedings of the Construction Research Congress 2018: Construction Information Technology, New Orleans, LA, USA, 2-4 April 2018.

9. Asadi, K.; Ramshankar, H.; Pullagurla, H.; Bhandare, A.; Shanbhag, S.; Mehta, P.; Kundu, S.; Han, K.; Lobaton, E.; Wu, T. Vision-based integrated mobile robotic system for real-time applications in construction. Autom. Constr. 2018, 96, 470-482. [CrossRef]

10. Asadi, K.; Jain, R.; Qin, Z.; Sun, M.; Noghabaei, M.; Cole, J.; Han, K.; Lobaton, E. Vision-based Obstacle Removal System for Autonomous Ground Vehicles Using a Robotic Arm. In Proceedings of the Computing in Civil Engineering 2019, Atlanta, GA, USA, 17-19 June 2019; pp. 328-335.

11. NBS Organization National BIM Report 2018. Available online: http://117.128.6.30/cache/www. bimacademy.global/wp-content/uploads/2018/05/NBS0850-BIM-Report-2018-LR-.pdf?ich_args2=46113100320036380_a2d9414520b4178e174666c7b55fd73d_10001002_9c896c28d7c5f5d89e3d518939a83798_ 83be1a351da14faf470d68f5c2cecc0a (accessed on 13 March 2020).

12. Chong, H.Y.; Lopez, R.; Wang, J.; Wang, X.; Zhao, Z. Comparative Analysis on the Adoption and Use of BIM in Road Infrastructure Projects. J. Manag. Eng. 2016, 32. [CrossRef]

13. Liao, L.; Ai Lin Teo, E. Organizational Change Perspective on People Management in BIM Implementation in Building Projects. J. Manag. Eng. 2018, 34. [CrossRef]

14. Ghaffarianhoseini, A.; Tookey, J.; Ghaffarianhoseini, A.; Naismith, N.; Azhar, S.; Efimova, O.; Raahemifar, K. Building Information Modelling (BIM) uptake: Clear benefits, understanding its implementation, risks and challenges. Renew. Sustain. Energy Rev. 2017, 75, 1046-1053. [CrossRef]

15. Du, J.; Shi, Y.; Zou, Z.; Zhao, D. CoVR: Cloud-Based Multiuser Virtual Reality Headset System for Project Communication of Remote Users. J. Constr. Eng. Manag. 2018, 144. [CrossRef] 
16. Wang, X.; Love, P.E.D.; Kim, M.J.; Park, C.S.; Sing, C.P.; Hou, L. A conceptual framework for integrating building information modeling with augmented reality. Autom. Constr. 2013, 34, 37-44. [CrossRef]

17. Noghabaei, M.; Asadi, K.; Han, K. Virtual Manipulation in an Immersive Virtual Environment: Simulation of Virtual Assembly. In Proceedings of the Computing in Civil Engineering 2019, Atlanta, GA, USA, 17-19 June 2019; pp. 95-102. [CrossRef]

18. Biocca, F.; Levy, M.R.; Kim, T.; Levy, M.R. Communication in the Age of Virtual Reality (Routledge Communication Series); CRC Press: Boca Raton, FL, USA, 2013; ISBN 1135693579.

19. Dossick, C.S.; Anderson, A.; Azari, R.; Iorio, J.; Neff, G.; Taylor, J.E. Messy Talk in Virtual Teams: Achieving Knowledge Synthesis through Shared Visualizations. J. Manag. Eng. 2015, 31. [CrossRef]

20. Berg, L.P.; Vance, J.M. Industry use of virtual reality in product design and manufacturing: A survey. Virtual Real. 2017, 21, 1-17. [CrossRef]

21. Choi, S.; Jung, K.; Noh, S. Do Virtual reality applications in manufacturing industries: Past research, present findings, and future directions. Concurr. Eng. 2015, 23, 40-63. [CrossRef]

22. Dacko, S.G. Enabling smart retail settings via mobile augmented reality shopping apps. Technol. Forecast. Soc. Change 2017, 124, 243-256. [CrossRef]

23. Bonetti, F.; Warnaby, G.; Quinn, L. Augmented Reality and Virtual Reality in Physical and Online Retailing: A Review, Synthesis and Research Agenda. In Augmented Reality and Virtual Reality; Jung, T., Tom Dieck, M., Eds.; Springer: Cham, Switzerland, 2018; pp. 119-132.

24. Zhang, H. Head-mounted display-based intuitive virtual reality training system for the mining industry. Int. J. Min. Sci. Technol. 2017, 27, 717-722. [CrossRef]

25. Pedram, S.; Perez, P.; Palmisano, S.; Farrelly, M. Evaluating 360-Virtual Reality for Mining Industry's Safety Training. In HCI International 2017-Posters' Extended Abstracts. HCI 2017. Communications in Computer and Information Science; Stephanidis, C., Ed.; Springer: Cham, Switzerland, 2017; pp. 555-561.

26. Merchant, Z.; Goetz, E.T.; Cifuentes, L.; Keeney-kennicutt, W.; Davis, J. Computers \& Education Effectiveness of virtual reality-based instruction on students' learning outcomes in K-12 and higher education: A meta-analysis. Comput. Educ. 2014, 70, 29-40.

27. Zhang, M.; Zhang, Z.; Chang, Y.; Aziz, E.-S.; Esche, S.; Chassapis, C. Recent Developments in Game-Based Virtual Reality Educational Laboratories Using the Microsoft Kinect. Int. J. Emerg. Technol. Learn. 2018, 13, 138-159. [CrossRef]

28. Greenwald, S.; Kulik, A.; Kunert, A.; Beck, S.; Frohlich, B.; Cobb, S.; Parsons, S.; Newbutt, N.; Gouveia, C.; Cook, C. Technology and applications for collaborative learning in virtual reality. Available online: https://uwe-repository.worktribe.com/output/886338 (accessed on 3 December 2019).

29. Khor, W.S.; Baker, B.; Amin, K.; Chan, A.; Patel, K.; Wong, J. Augmented and virtual reality in surgery - the digital surgical environment: Applications, limitations and legal pitfalls. Ann. Transl. Med. 2016, 4, 1-10. [CrossRef]

30. De Ribaupierre, S.; Kapralos, B.; Haji, F.; Stroulia, E.; Dubrowski, A.; Eagleson, R. Healthcare training enhancement through virtual reality and serious games. In Virtual, Augmented Reality and Serious Games for Healthcare 1; Ma, M., Jain, L., Anderson, P., Eds.; Springer: Berlin/Heidelberg, Germany, 2014; pp. 9-27.

31. Atwal, A.; Money, A.; Harvey, M. Occupational therapists' views on using a virtual reality interior design application within the pre-discharge home visit process. J. Med. Internet Res. 2014, 16. [CrossRef]

32. Li, X.; Yi, W.; Chi, H.; Wang, X.; Chan, A.P.C. Automation in Construction A critical review of virtual and augmented reality (VR/AR) applications in construction safety. Autom. Constr. 2018, 86, 150-162. [CrossRef]

33. Paes, D.; Arantes, E.; Irizarry, J. Immersive environment for improving the understanding of architectural 3D models: Comparing user spatial perception between immersive and traditional virtual reality systems. Autom. Constr. 2017, 84, 292-303. [CrossRef]

34. Fogarty, J.; McCormick, J.; El-Tawil, S. Improving Student Understanding of Complex Spatial Arrangements with Virtual Reality. J. Prof. Issues Eng. Educ. Pract. 2018, 144. [CrossRef]

35. Niu, S.; Pan, W.; Zhao, Y. A virtual reality integrated design approach to improving occupancy information integrity for closing the building energy performance gap. Sustain. Cities Soc. 2016, 27, 275-286. [CrossRef]

36. Javornik, A. Augmented reality: Research agenda for studying the impact of its media characteristics on consumer behaviour. J. Retail. Consum. Serv. 2016, 30, 252-261. [CrossRef]

37. McCormick, H.; Cartwright, J.; Perry, P.; Barnes, L.; Lynch, S.; Ball, G. Fashion retailing—past, present and future. Text. Prog. 2014, 46, 227-321. [CrossRef] 
38. Grabowski, A.; Jankowski, J. Virtual Reality-based pilot training for underground coal miners. Saf. Sci. 2015, 72, 310-314. [CrossRef]

39. Mosadeghi, S.; Reid, M.W.; Martinez, B.; Rosen, B.T.; Spiegel, B.M.R. Feasibility of an Immersive Virtual Reality Intervention for Hospitalized Patients: An Observational Cohort Study. JMIR Ment. Heal. 2016, 3, e28. [CrossRef]

40. Tashjian, V.C.; Mosadeghi, S.; Howard, A.R.; Lopez, M.; Dupuy, T.; Reid, M.; Martinez, B.; Ahmed, S.; Dailey, F.; Robbins, K.; et al. Virtual Reality for Management of Pain in Hospitalized Patients: Results of a Controlled Trial. JMIR Ment. Heal. 2017, 4, e9. [CrossRef]

41. Dascal, J.; Reid, M.; IsHak, W.W.; Spiegel, B.; Recacho, J.; Rosen, B.; Danovitch, I. Virtual Reality and Medical Inpatients: A Systematic Review of Randomized, Controlled Trials. Innov. Clin. Neurosci. 2017, 14, 14-21.

42. Pelargos, P.E.; Nagasawa, D.T.; Lagman, C.; Tenn, S.; Demos, J.V.; Lee, S.J.; Bui, T.T.; Barnette, N.E.; Bhatt, N.S.; Ung, N.; et al. Utilizing virtual and augmented reality for educational and clinical enhancements in neurosurgery. J. Clin. Neurosci. 2017, 35, 1-4. [CrossRef]

43. Akçayır, M.; Akçayır, G. Advantages and challenges associated with augmented reality for education: A systematic review of the literature. Educ. Res. Rev. 2017, 20,1-11. [CrossRef]

44. Potkonjak, V.; Gardner, M.; Callaghan, V.; Mattila, P.; Guetl, C.; Petrović, V.M.; Jovanović, K. Virtual laboratories for education in science, technology, and engineering: A review. Comput. Educ. 2016, 95, 309-327. [CrossRef]

45. Wei, X.; Weng, D.; Liu, Y.; Wang, Y. Teaching based on augmented reality for a technical creative design course. Comput. Educ. 2015, 81, 221-234. [CrossRef]

46. Nikolic, D.; Jaruhar, S.; Messner, J.I. An Educational Simulation in Construction: The Virtual Construction Simulator. Comput. Civ. Eng. 2009, 25, 633-642.

47. Li, R.Y.M. Virtual Reality and Construction Safety. In An Economic Analysis on Automated Construction Safety; Springer: Singapore, 2018; pp. 117-136.

48. Sacks, R.; Perlman, A.; Barak, R. Construction safety training using immersive virtual reality. Constr. Manag. Econ. 2013, 31, 1005-1017. [CrossRef]

49. Le, Q.T.; Pedro, A.; Park, C.S. A social virtual reality based construction safety education system for experiential learning. J. Intell. Robot. Syst. 2015, 79, 487-506. [CrossRef]

50. Jeelani, I.; Han, K.; Albert, A. Development of Immersive Personalized Training Environment for Construction Workers. In Proceedings of the Congress on Computing in Civil Engineering, Seattle, WC, USA, 25-27 June 2017.

51. Balali, V.; Noghabaei, M.; Heydarian, A.; Han, K. Improved Stakeholder Communication and Visualizations: Real-Time Interaction and Cost Estimation within Immersive Virtual Environments. In Proceedings of the Construction Research Congress, New Orleans, LA, USA, 2-4 April 2018; pp. 522-530.

52. Williams, G.; Gheisari, M.; Chen, P.-J.; Irizarry, J. BIM2MAR: An Efficient BIM Translation to Mobile Augmented Reality Applications. J. Manag. Eng. 2015, 31. [CrossRef]

53. Noghabaei, M.; Han, K. Hazard recognition in an immersive virtual environment: Framework for the simultaneous analysis of visual search and EEG patterns. Available online: https://www.researchgate.net/publication/337821155_Hazard_recognition_in_an_immersive_virtual_ environment_Framework_for_the_simultaneous_analysis_of_visual_search_and_EEG_patterns (accessed on 13 March 2020).

54. Moore, H.; Eiris, R.; Gheisari, M.; Esmaeili, B. Hazard Identification Training Using 360-Degree Panorama vs. Virtual Reality Techniques: A Pilot Study. Am. Soc. Civ. Eng. 2019. [CrossRef]

55. Eiris, R.; Gheisari, M.; Esmaeili, B.; Eiris, R.; Gheisari, M.; Esmaeili, B. PARS: Using Augmented 360-Degree Panoramas of Reality for Construction Safety Training. Int. J. Environ. Res. Public Health 2018, 15, 2452. [CrossRef]

56. Zou, Z.; Yu, X.; Ergan, S. Visualization (nD, VR, AR). In Proceedings of the Computing in Civil Engineering, Atlanta, GA, USA, 17-19 June 2019; pp. 169-176.

57. Ergan, S.; Radwan, A.; Zou, Z.; Tseng, H.; Han, X. Quantifying Human Experience in Architectural Spaces with Integrated Virtual Reality and Body Sensor Networks. J. Comput. Civ. Eng. 2019, 33. [CrossRef]

58. Goulding, J.; Nadim, W.; Petridis, P.; Alshawi, M. Construction industry offsite production: A virtual reality interactive training environment prototype. Adv. Eng. Informatics 2012, 26, 103-116. [CrossRef] 
59. Fang, Y.; Cho, Y.K. A framework of lift virtual prototyping (LVP) approach for crane safety planning. In Proceedings of the 33th International Symposium on Automation and Robotics in Construction (ISARC 2016), Auburn, AL, USA, 18-21 July 2016.

60. Kayhani, N.; Taghaddos, H.; Noghabaee, M.; Hermann, U. Utilization of Virtual Reality Visualizations on Heavy Mobile Crane Planning for Modular Construction. arXiv 2019, arXiv:1901.06248. Available online: https://arxiv.org/abs/1901.06248 (accessed on 10 March 2020).

61. Birt, J.; Manyuru, P.; Nelson, J. Using virtual and augmented reality to study architectural lighting. 2017. Available online: http://2017conference.ascilite.org/wp-content/uploads/2017/11/Concise-BIRT.pdf (accessed on 13 March 2020).

62. Kuliga, S.F.; Thrash, T.; Dalton, R.C.; Hölscher, C. Computers, Environment and Urban Systems Virtual reality as an empirical research tool - Exploring user experience in a real building and a corresponding virtual model. CEUS 2015, 54, 363-375.

63. Heydarian, A.; Carneiro, J.P.; Gerber, D.; Becerik-gerber, B.; Hayes, T.; Wood, W. Automation in Construction Immersive virtual environments versus physical built environments: A benchmarking study for building design and user-built environment explorations. Autom. Constr. 2015, 54, 116-126. [CrossRef]

64. Heydarian, A.; Pantazis, E.; Wang, A.; Gerber, D.; Becerik-Gerber, B. Towards user centered building design: Identifying end-user lighting preferences via immersive virtual environments. Autom. Constr. 2017, 81, 56-66. [CrossRef]

65. Heydarian, A.; Pantazis, E.; Carneiro, J.P.; Gerber, D.; Becerik-Gerber, B. Lights, building, action: Impact of default lighting settings on occupant behaviour. J. Environ. Psychol. 2016, 48, 212-223. [CrossRef]

(C) 2020 by the authors. Licensee MDPI, Basel, Switzerland. This article is an open access article distributed under the terms and conditions of the Creative Commons Attribution (CC BY) license (http://creativecommons.org/licenses/by/4.0/). 